\title{
Transatlantica
}

Revue d'études américaines. American Studies Journal

\section{Marie-Christine Agosto. Richard Brautigan. Les fleurs de néant.}

Paris : Belin, 1999. 128 p.http://www.editions-belin.com

\section{Jean-Bernard Basse}

\section{(2) OpenEdition}

\section{Journals}

Édition électronique

URL : http://journals.openedition.org/transatlantica/709

DOI : $10.4000 /$ transatlantica.709

ISSN : 1765-2766

Éditeur

AFEA

Référence électronique

Jean-Bernard Basse, " Marie-Christine Agosto. Richard Brautigan. Les fleurs de néant. », Transatlantica

[En ligne], 1 | 2003, mis en ligne le 05 avril 2006, consulté le 29 avril 2021. URL : http://

journals.openedition.org/transatlantica/709; DOI : https://doi.org/10.4000/transatlantica.709

Ce document a été généré automatiquement le 29 avril 2021.

\section{c) (i) $\odot$}

Transatlantica - Revue d'études américaines est mis à disposition selon les termes de la licence Creative Commons Attribution - Pas d'Utilisation Commerciale - Pas de Modification 4.0 International. 


\title{
Marie-Christine Agosto. Richard Brautigan. Les fleurs de néant.
}

\author{
Paris : Belin, 1999. 128 p.http://www.editions-belin.com
}

Jean-Bernard Basse

1 Richard Brautigan, si on lui reconnaît un certain humour, est souvent associé avec condescendance au phénomène hippy et considéré comme un auteur démodé, superficiel. Celui qui écrivait dans Cahier d'un Retour de Troie : «Les mots sont des fleurs de néant » est pourtant l'un de ces écrivains que l'on pourrait qualifier de mineurs essentiels, et seuls ceux qui l'ont peu ou mal lu s'étonneront de ce que Marie-Christine Agosto ait choisi de donner comme sous-titre «Les fleurs de néant » au petit volume qu'elle lui consacre dans la collection dirigée par Marc Chénetier. On peut écrire des textes courts, apparemment désinvoltes, fragmentés, faussement simples, pour dire l'angoisse née de l'écoulement du temps, de l'oubli, de la perte de l'innocence.

Dans son étude exhaustive, M.-C. Agosto rappelle qu'on distingue trois périodes dans l'oeuvre de Brautigan, correspondant à trois types de contenu et d'écriture: la première semble dresser un état des lieux de l'Amérique, où la veine écologique, pseudo-pastorale, s'appuie sur des techniques de mise en morceaux, de démontage historique, culturel et textuel (Un Général sudiste de Big Sur, La Pêche à la truite en Amérique); la seconde où il s'attaque aux genres littéraires dans des parodies de romans (sentimental dans L'Avortement, western et gothique dans Le Monstre des Hawkline, japonais dans Retombées de sombrero, policier dans Un Privé à Babylone ...) ; et la troisième, à l'écriture plus dépouillée, où l'examen du quotidien, associé à une tentative de bilan personnel, vire à la tristesse, à l'amertume. C'est, écrit-elle, « une oeuvre qui commence dans la fantaisie provocatrice et se termine dans la résignation amère. »

Mais au fond, si la tonalité et la thématique des écrits de Brautigan changent avec le temps, M.-C. Agosto montre la permanence des procédés qu'il affectionne. On retrouve souvent l'utilisation de bribes d'écrits, inachevés, effacés, de fragments qui semblent arrachés à l'usure du temps, de textes où le blanc, le silence, et parfois quelque digression intempestive semblent plus importants que le récit lui-même. Quand l'accidentel tient lieu de logique, l'auteur multiplie les parataxes, les associations 
d'éléments souvent hétéroclites; aux constructions causales il préfère les juxtapositions incongrues. Ici, avec une feinte naïveté, c'est la disparition des valeurs de l'Amérique mythique qui est marquée, là c'est l'écart entre l'expérience individuelle et le déroulement de l'Histoire. Ailleurs, l'humour met en évidence l'inadéquation du langage et du réel. Aussitôt son sourire effacé, le lecteur sent monter une angoisse que provoquent l'échec omniprésent, le sentiment de perte de contrôle, d'impuissance à comprendre quoi que ce soit.

Dans la même veine M.-C. Agosto analyse avec justesse les dédoublements fréquents chez Brautigan, où les personnages vont par paires, soulignant des identités incertaines, jouant avec des caractérisations rudimentaires de bandes dessinées, et exacerbant parfois le vertige quand le miroir renvoie du vide. Et si, dans ces livres, le sentiment d'attente, de stase, prédomine, si l'incapacité des personnages à accomplir ce pour quoi ils sont programmés est quasi-systématique, le lecteur est tenu en haleine, malgré la multiplication des procédés de distortion du temps (prolepses fréquentes) comme s'il voulait savoir ce qui ne se passera pas ensuite. C'est ici que les célèbres images brautiganiennes prennent toute leur importance. L'auteur subvertit le discours par l'imaginaire, lui donne une tonalité loufoque et surréaliste. Avec l'audace et l'incongruité de ses comparaisons, il crée un langage en perpétuelle effervescence, il "substitue le jaillissement désordonné de l'imaginaire au récit traditionnel, militaire, codifié et régimenté». C'est une des raisons pour lesquelles Brautigan regrette l'enfance, cet état d'avant la pensée rationnelle, et s'efforce de retrouver l'innocence d'un tel regard, capable de créer à partir de rien. Ici encore, avec cette vision du fonctionnement de l'imaginaire « comme on épluche un oignon jusqu'à le réduire à un rond de plus en plus petit et que les larmes viennent aux yeux jusqu'à ce qu'il n'y ait plus d'oignon, que je l'aie épluché complètement et que je cesse de peurer », Brautigan cache mal sa fascination du vide. Certains de ses textes donnent parfois l'impression de s'effacer progressivement, au fur et à mesure qu'ils sont écrits et, comme le note M.-C. Agosto, « si les premiers livres de Brautigan créaient des images sur le vide, les derniers écrits ne peuvent plus que dire et cerner le vide " à l'instar de Cahier d'un Retour de Troie, livre posthume, "suite de digressions, de parenthèses, de détours et d'ébauches, dont le but avoué est de tuer le temps avant qu'il ne vous tue lui-même ", récit plein de trous, d'oublis, où les questions s'accumulent, sans réponse.

\section{INDEX}

Thèmes : Recensions

\section{AUTEUR}

JEAN-BERNARD BASSE

Université Paris 10 - Nanterre 